\title{
UTAUT Model: Suatu Pendekatan Evaluasi Penerimaan E-Learning pada Program Pascasarjana
}

\author{
${ }^{1}$ Ridwan Daud Mahande, ${ }^{2}$ Jasruddin \\ ${ }^{1}$ Universitas Pepabri Makassar dan ${ }^{2}$ Universitas Negeri Makassar \\ ridho84dm@gmail.com
}

\begin{abstract}
Abstrak - Kualitas implementasi e-learning akan selalu berhubungan dengan penerimaan pengguna secara sukarela. Sejauhmana penerimaan pengguna terhadap e-learning memerlukan suatu pendekatan evaluasi yang mampu menyelidiki faktor-faktor penentu penerimaan e-learning. Model unified theory of acceptance and use of technology (UTAUT) adalah sintesis model penerimaan teknologi yang akan tepat digunakan sebagai model evaluasi e-learning. Model evaluasi penerimaan e-learning akan menekankan pada empat kunci konstruk dari UTAUT, yaitu: harapan kinerja, harapan usaha, pengaruh sosial, dan kondisi fasilitas terhadap niat untuk menerima e-learning. Studi ini merupakan studi awal yang diharapkan dapat menjadi acuan dalam perumusan kebijakan mengenai implementasi dan pengembangan e-learning yang berkelanjutan pada program pascasarjana
\end{abstract}

Kata kunci: UTAUT model, evaluasi penerimaan e-learning, program pascasarjana

\section{PENDAHULUAN}

Teknologi Informasi dan Komunikasi (TIK) merupakan alat bantu dalam menyelesaikan permasalahan yang dihadapi dalam berbagai sektor kehidupan termasuk sektor pendidikan. Pemanfaatan TIK akan dapat memberikan implikasi kinerja yang lebih baik (Venkatesh et al., 2003). Begitu pun dengan lembaga pendidikan di perguruan tinggi. Perguruan tinggi menyadari pentingnya TIK sebagai aset yang berharga dan memahami keuntungan dan kegunaan dari TIK untuk mendukung kinerja (Nasir, 2013). Selain itu, perguruan tinggi juga memahami dan mengelola resikoresiko yang berhubungan dengan aktivitas pendidikan yang bergantung pada TIK.

Program Pascasarjana sebagai bagian dari lembaga pendidikan di perguruan tinggi merespon pentingnya pemanfaatan TIK tersebut. Hal ini senada dengan tuntutan Program Pascasarjana dalam membekali mahasiswa dan lulusannya dengan kompetensi kognitif, sikap dan keterampilan yang memadai. Pembelajaran berbasis TIK adalah bentuk dari penyiapan tersebut. Salah satunya melalui penggunaan sistem e-learning dalam pendidikan dan pembelajaran. E-learning adalah proses pembelajaran yang memanfaatkan TIK secara sistematis dengan mengintegrasikan semua komponen pembelajaran, termasuk interaksi pembelajaran lintas ruang dan waktu, dengan kualitas yang terjamin (Sedana and Wijaya, 2010). Ditambahkan oleh Yulius (2016) bahwa e-learning merupakan ragam teknologi informasi yang memfasilitasi proses pembelajaran dan memungkinkan lembaga pendidikan mengurangi biaya dan meningkatkan ketersediaan pendidikan.

E-learning telah diimplementasikan dalam pembelajaran, namun e-learning sangat membutuhkan evaluasi yang baik dan terencana sebagai bahan rekomendasi dan perbaikan lebih lanjut. Evaluasi terhadap implementasi e-learning dilakukan untuk menguji efektivitas dari sistem e-learning yang selama ini diselenggarakan. Kualitas e-learning dapat dikatakan baik apabila e-learning tersebut teruji dan selalu dilakukan revisi atau perbaikan terhadap sistem dan penyelenggaraannya (Yulius (2016). Evaluasi ini merupakan salah satu langkah penting dalam mengukur kualitas penyelenggaraan $e$ - learning yang dilakukan. Beberapa penelitian menjelaskan bahwa kualitas implementasi teknologi informasi seperti halnya e-learning akan selalu berhubungan dengan penerimaan pengguna secara sukarela (Nasir, 2013; Yulius, 2016). Oleh karena itu, sejauhmana pemahaman dan penerimaan pengguna (dosen dan mahasiswa) terhadap implementasi e-learning adalah hal yang menentukan kualitas keberhasilan dari penyelenggaraan tersebut.

Sehubungan dengan penjelasan tersebut, diperlukan suatu pendekatan evaluasi sebagai solusinya. Karena, penekanan evaluasi pada penerimaan pengguna terhadap $e$ learning, maka model penerimaan teknologi dianggap paling tepat untuk digunakan. Salah satu model penerimaan teknologi yang banyak digunakan adalah unified theory of acceptance and use of technology (UTAUT). UTAUT model sebagai sintesis komprehensif sebelum penelitian penerimaan teknologi. UTAUT model telah mengalami perkembangan dari sebelumnya memilki empat kunci konstruk, yaitu: harapan kinerja (performance expectancy), harapan usaha (effort expectancy), pengaruh sosial (social influence), dan kondisi fasilitas (facilitating conditions) terhadap niat (behavior intention) untuk penerimaan teknologi (use technology). Saat ini, UTAUT2 menambahkan tiga konstruk baru yang ditambahkan pada UTAUT lama yaitu: motivasi hedonis (hedonic motivation), hitungan harga (price value), dan kebiasaan (habit) (Venkatesh et al., 2012).

Penelitian-penelitian yang terpublikasi dari berbagai negara menujukkan bahwa UTAUT model terbukti secara empiris mampu menjelaskan penerimaan teknologi $e$ learning. Kesiapan dan penerimaan terhadap e-learning di Thailand (Ngampornchai and Adams, 2016); intensi penggunaan e-learning di Kroasia (Babie et al., 2016); dan model penerimaan e-learning di Macedonia (E-learning Center - University "Goce Delcev", Stip, 2000, R.Macedonia et al., 2015). Sedangkan di Indonesia sendiri, studi empiris penerimaan dan penggunaan sistem $e$ learning (Agustin and Mulyani, 2016); penerimaan pengguna terhadap implemntasi e-learning (Haris and Sugito, 2015), model evaluasi kesuksesan dan penerimaan sistem e-learning (Pamugar et al., 2014); dan kajian penerimaan e-learning (Prasetyo and Anubhakti, 2011). 
Penelitian tersebut mempertegas bahwa UTAUT model telah digunakan untuk mengevaluasi penerimaan e-learning di beberapa Negara termasuk Indonesia. Namun pengembangan konstruk dari UTAUT model berbeda-beda sesuai konteks penelitian. Pada hasil penelitian yang lebih luas, studi ini akan menghasilkan (1) gambaran pelaksanaan e-learning yang selama ini dilakukan ditinjau dari model UTAUT, (2) menunjukkan faktor yang memberikan sumbangsih terhadap evaluasi penerimaan e-learning, (3) alternatif model evaluasi penerimaan e-learning. Akan tetapi, dalam studi awal ini hanya akan fokus pada eksplorasi konstruk UTAUT sesuai konteks dimana penelitian akan dilakukan. Studi awal ini menghasilkan model konseptual evaluasi penerimaan e-learning pada program pascasarjana

\section{KONSEP E-LEARNING}

Konsep e-learning merupakan suatu teknologi pembelajaran baru berbasis TIK yang telah diterima dalam pendidikan. Penerimaan ini sangat beralasan dalam rangka penyiapan SDM dengan kemampuan TIK untuk mengatasi masalah ketenagakerjaan dan stabilitas perekonomian (Inayat et al., 2013). Selain itu, e-learning merupakan bagian dari TIK yang sudah menjadi kompetensi utama dalam kehidupan sosial dan dunia kerja (Loogma et al., 2012).

Konsep e-learning menurut Horton and Horton, (2003) adalah penggunaan teknologi web dan internet untuk menciptakan pengalaman belajar. Lebih lanjut, Khan, (2005) menyatakan bahwa e-learning merupakan pendekatan inovatif untuk mengirimkan materi pembelajaran interaktif kepada siapa pun, di mana pun, kapan pun, dengan menggunakan berbagai atribut dan sumber daya berbagai teknologi digital dalam lingkungan pembelajaran yang terbuka, fleksibel, dan terdistribusi. Sehubungan dengan teknologi digital atau elektronik yang dimaksud, Gilbert and Jones, (2001) menyatakan bahwa $e$ learning merupakan pengiriman materi pembelajaran melalui suatu media elektronik seperti, internet, intranet/ekstranet, satelit broadcast, audio/video tape, TV interaktif, CD-ROM, dan computer based training.

Penggunaan e-learning memiliki berbagai kelebihan, yaitu (1) peserta didik dapat belajar kapan saja dan dari mana saja, (2) materi diperkaya dengan berbagai sumber belajar, (3) materi pembelajaran dapat dengan mudah diperbaharui, (4) link ke sumber daya lain lebih mudah, (4) kolaborasi yang mudah diatur, (5) berbagai quiz online yang tersedia, dan (6) peserta didik dapat mengirimkan tugas dalam beberapa format media (Surjono, 2013).

Walaupun demikian, e-learning juga tidak terlepas dari berbagai kekurangan, di antaranya (1) kurangnya interaksi antara guru dan siswa yang bisa memperlambat terbentuknya values dalam proses belajar dan mengajar; (2) tidak semua tempat tersedia fasilitas internet; (3) kurangnya tenaga yang mengetahui dan memiliki keterampilan mengoperasikan internet; (4) kurangnya penguasaan bahasa pemrograman computer (Bullen \& Beam dalam Riyana and Deni Kurniawan, 2011). Kekurangan e-learning merupakan hambatan sekaligus tantangan bagi lembaga pendidikan pada program pascasarjana. Oleh karena itu, program pascasarjana penting untuk merumuskan strategi untuk mengatasi faktor- faktor yang menjadi penghambat implementasi e-learning. Upaya yang perlu dilakukan menurut Ahmed, (2013), yaitu (a) menciptakan budaya yang mendukung ke arah $e$ learning; (b) memberikan insentif untuk memotivasi dosen/instruktur; (c) memberikan internet terkait dan pelatihan komputer; (d) terus membangun aplikasi $e$ learning yang lebih fleksibel dan mudah digunakan; (e) meningkatkan kesadaran tentang pentingnya e-learning sebagai media yang berguna untuk dosen/instruktur dan tujuan pendidikan.

Hal tersebut dapat dilakukan jika lembaga mengembangkan visi terkoordinasi untuk perubahan teknologi yang efektif serta dapat memandu proses $e$ learning (Rossner \& Stockley Khan, 2005). Selain itu, uraian kelebihan dan kekurangan/tantangan e-learning tersebut perlu mendapat perhatian khusus melalui sebuah evaluasi apakah kelebihan-kelebihan tersebut sudah dimanfaatkan dengan baik ataukah tidak. Sementara, kekurangan-kekurangan yang ditunjukkan apakah dapat diperbaiki atau ditingkatkan. Oleh sebab itu, penyelenggaraan e-learning dalam institusi pendidikan khususnya di program pascasarjana perlu melakukan evaluasi secara berkala. Evaluasi menyangkut penerimaan sangat penting untuk dilakukan, karena implementasi $e$ learning akan berhasil jika diterima dengan baik oleh pengguna. Beberapa model penerimaan telah digunakan dalam rangka mengevaluasi penerimaan e-learning, yaitu salah satunya adalah Unified Theory of Acceptance and Use of Technology (UTAUT).

\section{MODEL UTAUT}

Model Unified Theory of Acceptance and Use of Technology (UTAUT) adalah model terpadu yang dikembangkan oleh Venkatesh et al (2003) berdasarkan teori sosial kognitif dengan kombinasi delapan model penelitian terkemuka mengenai penerimaan teknologi informasi (Taiwo and Downe, 2013). Model UTAUT telah terbukti berhasil dari delapan teori penerimaan teknologi yang lain dalam menjelaskan hingga $70 \%$ varian pengguna (Taiwo and Downe, 2013; Nasir, 2013). Model UTAUT (Venkatesh et al., 2003) kemudian mengalami perkembangan dengan penambahan beberapa variabel (Venkatesh et al., 2012). Model UTAUT lama memiliki empat kunci konstruksi yaitu: harapan kinerja (performance expectancy), harapan usaha (effort expectancy), pengaruh sosial (social influence), dan kondisi fasilitas (facilitating conditions) yang memiliki pengaruh terhadap niat perilaku untuk menggunakan teknologi.

Performance expectancy adalah sejauh mana seorang individu percaya bahwa menggunakan sistem akan membantu dia untuk mencapai keuntungan dalam pekerjaan atau kegiatan tertentu. Effort expectancy adalah tingkat kemudahan terkait dengan penggunaan sistem/teknologi oleh pengguna. Social influence adalah sejauhmana persepsi seseorang bahwa pihak lain percaya bahwa sebaiknya menggunakan sistem/teknologi. Facilitating conditions adalah sejauh mana seorang individu percaya bahwa infrastruktur teknis dan organisasi tersedia untuk mendukung penggunaan sistem/teknologi (Venkatesh et al., 2012; Chang, 2012). Model UTAUT menekankan bahwa performance expectancy, effort expectancy, social influence dan facilitating conditions secara teori dan empiris memengaruhi niat perilaku (behavioral intention) untuk 
menggunakan suatu sistem/teknologi. Sedangkan behavioral intention dan facilitating conditions menentukan penggunaan sistem/teknologi (use behavior). Selain itu, variabel gender, age, dan experience digunakan sebagai variabel pembeda individu dalam melihat pengaruh kondisi fasilitas, price value, dan habit terhadap behavioral intention, serta experience sebagai pembeda individu untuk melihat pengaruh behavioral intention terhadap use behavior.

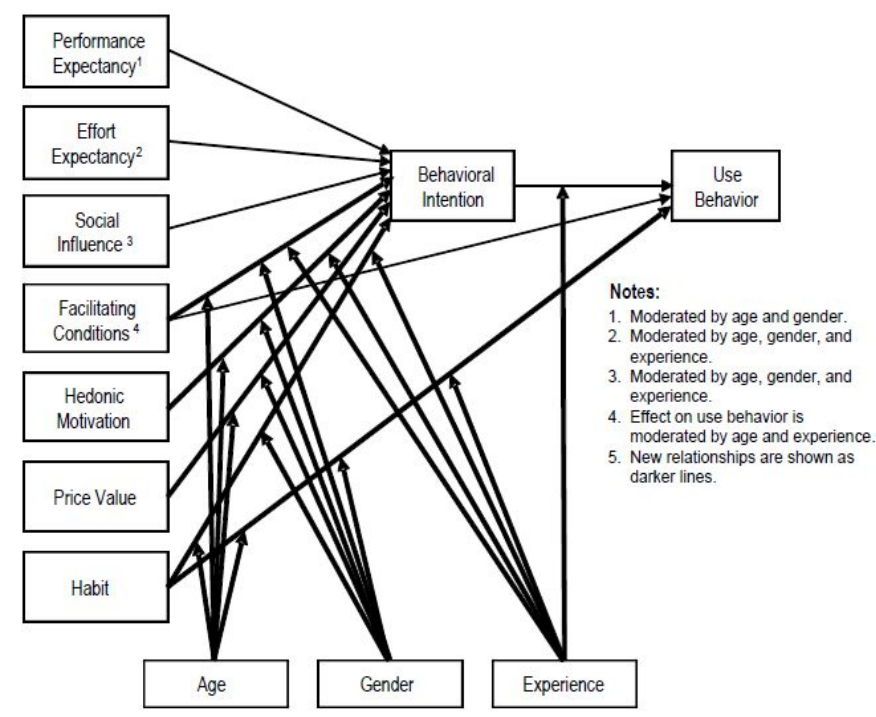

Gambar 1. UTAUT2 (Venkatesh et al., 2012:160)

Gambar 1 menunjukkan bahwa UTAUT2 menghasilkan tiga konstruk baru yang ditambahkan pada UTAUT lama yaitu: motivasi hedonis (hedonic motivation), harga (price value), dan kebiasaan atau habit (Venkatesh et al., 2012). Hedonic motivation didefinisikan sebagai hal yang menyenangkan atau kesenangan yang diperoleh saat menggunakan teknologi dan telah terbukti memainkan peran penting dalam menentukan penerimaan dan penggunaan sistem/teknologi (Chang, 2012; Venkatesh et al., 2012). Price value mengacu pada sejauh mana struktur biaya dan harga memiliki dampak signifikan terhadap penggunaan sistem/teknologi. Nilai harga sebagai prediktor niat perilaku untuk penggunaan suatu teknologi. Habit adalah sejauh mana individu cenderung untuk melakukan perilaku secara otomatis untuk belajar (Chang, 2012).

Berdasarkan teori tersebut, studi awal ini mengkaji beberapa hasil penelitian mengenai penggunaan UTAUT model dalam menganalisis penerimaan e-learning. Hasil kajian disajikan pada Tabel 1 berikut.

Tabel 1. Hasil Kajian Penelitian

\begin{tabular}{|c|l|l|l|}
\hline No & Peneliti & $\begin{array}{l}\text { Variabel UTAUT } \\
\text { yang digunakan dan } \\
\text { ditambahkan }\end{array}$ & $\begin{array}{l}\text { Variabel } \\
\text { eksternal yang } \\
\text { signifikan }\end{array}$ \\
\hline 1 & $\begin{array}{l}\text { Ngampornchai \& } \\
\text { Adams, 2016 }\end{array}$ & $\begin{array}{l}\text { Performance } \\
\text { expectancy, Effort } \\
\text { expectancy, attitude, } \\
\text { image, social } \\
\text { influence, } \\
\text { compatibility }\end{array}$ & $\begin{array}{l}\text { Performance } \\
\text { expectancy dan } \\
\text { effort expectancy }\end{array}$ \\
\hline 2 & Babie et al., 2016 & $\begin{array}{l}\text { Self efficacy, Social } \\
\text { influence }\end{array}$ & Social influence \\
\hline 3 & $\begin{array}{l}\text { E-learning Center - } \\
\text { University "Goce } \\
\text { Delcev", Stip, } \\
\text { 2000, R.Macedonia }\end{array}$ & $\begin{array}{l}\text { Performance } \\
\text { expectancy, Effort } \\
\text { expectancy, social } \\
\text { influence, self }\end{array}$ & $\begin{array}{l}\text { Effort } \\
\text { expectancy, } \\
\text { facilitating } \\
\text { conditions }\end{array}$ \\
\hline
\end{tabular}

\begin{tabular}{|c|c|c|c|}
\hline & et al., 2015 & $\begin{array}{l}\text { efficacy, attitude, self } \\
\text { confidence, } \\
\text { facilitating conditions }\end{array}$ & \\
\hline \multirow[t]{2}{*}{4} & $\begin{array}{l}\text { Maldonado et al., } \\
2009\end{array}$ & $\begin{array}{l}\text { Motivation, social } \\
\text { influence, facilitating } \\
\text { conditions }\end{array}$ & Social Influence \\
\hline & $\begin{array}{l}\text { Taiwo and Downe, } \\
2013\end{array}$ & $\begin{array}{l}\text { Performance } \\
\text { expectancy, Effort } \\
\text { expectancy, social } \\
\text { influence, facilitating } \\
\text { conditions }\end{array}$ & $\begin{array}{l}\text { Performance } \\
\text { expectancy }\end{array}$ \\
\hline 5 & $\begin{array}{l}\text { Agustin \& Mulyani, } \\
2016\end{array}$ & $\begin{array}{l}\text { Performance } \\
\text { expectancy, Effort } \\
\text { expectancy, social } \\
\text { influence, facilitating } \\
\text { conditions }\end{array}$ & $\begin{array}{l}\text { Performance } \\
\text { expectancy, } \\
\text { Effort } \\
\text { expectancy, } \\
\text { social influence }\end{array}$ \\
\hline 6 & $\begin{array}{l}\text { Haris \& Sugito, } \\
2015\end{array}$ & $\begin{array}{l}\text { Motivation, social } \\
\text { influence, content } \\
\text { quality, facilitating } \\
\text { conditions }\end{array}$ & Motivation \\
\hline 7 & $\begin{array}{l}\text { Pamugar et al., } \\
2014\end{array}$ & $\begin{array}{l}\text { Performance } \\
\text { expectancy, Effort } \\
\text { expectancy, } \\
\text { facilitating } \\
\text { conditions, partners } \\
\text { influence, top } \\
\text { management support, } \\
\text { organization support }\end{array}$ & $\begin{array}{l}\text { Masih sebatas } \\
\text { pengajuan } \\
\text { konseptual model } \\
\text { yang } \\
\text { memerlukan } \\
\text { pengujian }\end{array}$ \\
\hline 8 & $\begin{array}{l}\text { Prasetyo \& } \\
\text { Anubhakti, } 2011\end{array}$ & $\begin{array}{l}\text { Performance } \\
\text { expectancy, Effort } \\
\text { expectancy, social } \\
\text { influence, facilitating } \\
\text { conditions }\end{array}$ & $\begin{array}{l}\text { Masih sebatas } \\
\text { pengajuan } \\
\text { konseptual model } \\
\text { yang } \\
\text { memerlukan } \\
\text { pengujian } \\
\end{array}$ \\
\hline 9 & Fatmasari, 2011 & $\begin{array}{l}\text { Performance } \\
\text { expectancy, Effort } \\
\text { expectancy, social } \\
\text { influence }\end{array}$ & Social influence \\
\hline 10 & Nasir, 2013 & $\begin{array}{l}\text { Performance } \\
\text { expectancy, Effort } \\
\text { expectancy, social } \\
\text { influence }\end{array}$ & Effort expectancy \\
\hline 11 & $\begin{array}{l}\text { Mentaya et al., } \\
2015\end{array}$ & $\begin{array}{l}\text { Performance } \\
\text { expectancy, Effort } \\
\text { expectancy, social } \\
\text { influence }\end{array}$ & $\begin{array}{l}\text { Tidak ada yang } \\
\text { berpengaruh }\end{array}$ \\
\hline 12 & Faulina et al., 2017 & $\begin{array}{l}\text { Performance } \\
\text { expectancy, Effort } \\
\text { expectancy, social } \\
\text { influence }\end{array}$ & Social influence \\
\hline 13 & $\begin{array}{l}\text { Handayani and } \\
\text { Sudiana, } 2017\end{array}$ & $\begin{array}{l}\text { Performance } \\
\text { expectancy, Effort } \\
\text { expectancy, social } \\
\text { influence, facilitating } \\
\text { conditions }\end{array}$ & $\begin{array}{l}\text { Performance } \\
\text { expectancy, } \\
\text { social influence, } \\
\text { facilitating } \\
\text { conditions }\end{array}$ \\
\hline
\end{tabular}

Tabel 1 menunjukkan bahwa UTAUT model telah banyak digunakan untuk menelusuri penerimaan sistem/teknologi informasi, khususnya mengevaluasi penerimaan e-learning di beberapa Negara termasuk Indonesia. Namun pengembangan konstruk dari UTAUT model berbeda-beda sesuai konteks penelitian. Penelitian tersebut juga menunjukkan bahwa evaluasi penerimaan $e$ learning melalui pendekatan UTAUT model pada beberapa perguruan tinggi di Indonesia telah dilakukan. Namun dari hasil kajian literatur yang dilakukan menegaskan bahwa, penggunaan UTAUT model sebagai pendekatan riset evaluasi pada perguruan tinggi khususnya Program Pascasarjana belum mendapatkan perhatian atau dapat dikatakan belum pernah dilakukan. Dengan demikian, studi ini akan menggunakan pendekatan UTAUT model sebagai suatu pendekatan yang tepat dalam mengevaluasi penerimaan pengguna terhadap e-learning yang selama ini telah diimplementasikan. 
Pemilihan konstruk atau variabel pada UTAUT model berdasarkan hasil kajian penelitian relevan (Tabel 1). Hasil kajian penelitian relevan mengenai hubungan antar variabel UTAUT model menegaskan bahwa performance expectance memberikan pengaruh signifikan terhadap behavioral intention (Ngampornchai \& Adams, 2016; Agustin \& Mulyani, 2016; Handayani and Sudiana, 2017; Taiwo and Downe, 2013). Effort expectancy memberikan pengaruh terhadap behavioral intention (Ngampornchai \& Adams, 2016; E-learning Center - University "Goce Delcev", Stip, 2000, R.Macedonia et al., 2015; Agustin \& Mulyani, 2016; Nasir, 2013). Social influence memberikan pengaruh terhadap behavioral intention (Babie et al., 2016; Maldonado et al., 2009; Agustin \& Mulyani, 2016; Fatmasari, 2011; Faulina et al., 2017; Handayani and Sudiana, 2017). Facilitating conditions memberikan pengaruh terhadap behavioral intention dan acceptance elearning (E-learning Center - University "Goce Delcev", Stip, 2000, R.Macedonia et al., 2015; Handayani and Sudiana, 2017). Hampir semua peneliti tersebut menyatakan bahwa behavioral intention memberikan pengaruh tehadap acceptance e-learning. Sehubungan dengan itu, pemilihan variabel dalam penelitian ini berdasarkan penegasan dari beberapa peneliti tersebut dengan melihat tingkat signifikansi variabel hasil penelitian, kemudian menyesuaikan dengan kondisi atau kebutuhan riset evaluasi e-learning di Program Pascasarjana. Dengan demikian, studi awal ini menghasilkan model konseptual yang akan digunakan dalam penelitian lanjutan seperti pada gambar 2 .

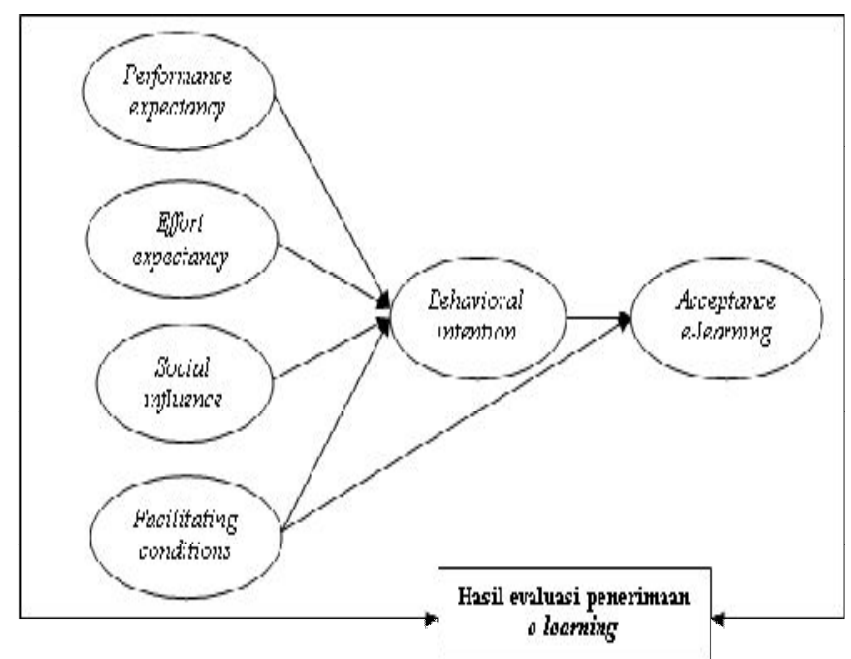

Gambar 2. Model konseptual evaluasi penerimaan $e$ learning

Gambar 2 menunjukkan bahwa variabel penelitian terdiri dari empat variabel eksogen yaitu variabel yang memengaruhi variabel lain dan dua variabel endogen yaitu variabel yang dipengaruhi oleh variabel lain. Ke-empat variabel eksogen tersebut adalah harapan kinerja atau performance expectancy ( $\mathrm{PE}$ ), harapan usaha atau effort expectancy (EE), pengaruh sosial atau social influence (SI), dan kondisi fasilitas atau facilitating conditions (FC). Sedangkan variabel endogen adalah niat perilaku atau behavioral intention (BI) dan penerimaan e-learning atau acceptance e-learning (AE).

\section{KESIMPULAN}

Evaluasi e-learning merupakan salah satu langkah penting dalam mengukur kualitas penyelenggaraan $e$ learning yang dilakukan pada Program Pascasarjana. Kualitas implementasi e-learning akan selalu berhubungan dengan penerimaan pengguna secara sukarela. Sejauhmana pemahaman dan penerimaan pengguna (dosen atau mahasiswa) terhadap implementasi e-learning adalah hal yang menentukan kualitas keberhasilan dari implementasi e-learning. Sesuai dengan tujuan evaluasi yang menekankan pada penerimaan, maka model penerimaan teknologi adalah model evaluasi yang tepat untuk digunakan. Unified theory of acceptance and use of technology (UTAUT) adalah sistesis komprehensif model penerimaan teknologi. Evaluasi penerimaan e-learning akan menekankan pada empat kunci konstruk dari UTAUT, yaitu: harapan kinerja, harapan usaha, pengaruh sosial, dan kondisi fasilitas terhadap niat untuk penerimaan e-learning. Studi awal ini diharapkan dapat menjadi acuan dalam perumusan kebijakan mengenai implementasi dan pengembangan e-learning yang berkelanjutan pada program pascasarjana.

Artikel ini merupakan studi awal penelitian PNBP Program Pascasarjana Universitas Negeri Makassar Tahun 2017. Saat ini, penelitian sedang dalam tahapan analisis dan hasilnya akan segera dipublikasikan pada jurnal internasional. Hasil penelitian ini berkontribusi lebih luas dalam memberikan gambaran pola pelaksanaan e-learning yang selama ini dilakukan, meunjukkan faktor yang memberikan sumbangsih terhadap evaluasi penerimaan $e$ learning, dan memberikan alternatif model evaluasi penerimaan e-learning.

\section{PUSTAKA}

[1] Agustin, H., Mulyani, E., 2016. Studi Empiris Penerimaan dan Penggunaan E-Learning System di Kalangan Mahasiswa Akuntansi Fakultas Ekonomi UNP, in: Seminar Nasional Aplikasi Teknologi Informasi (SNATI).

[2] Ahmed, T.T., 2013. Toward Successful E-Learning Implementation in Developing Countries: A Proposed Model for Predicting and Enhancing Higher Education Instructors' Participation. Int. J. Acad. Res. Bus. Soc. Sci. 3, 422.

[3] Babie, S., Čičin-Šain, M., Bubaš, G., 2016. A study of factors influencing higher education teachers' intention to use E-learning in hybrid environments, in: Information and Communication Technology, Electronics and Microelectronics (MIPRO), 2016 39th International Convention on. IEEE, pp. 998-1003.

[4] Banjuradja, A.M., 2015. TA: Faktor-Faktor Yang Berpengaruh Terhadap Penerimaan Aplikasi Brilian Dengan Model UTAUT. Stikom Surabaya.

[5] Chang, A., 2012. UTAUT and UTAUT 2: A Review and Agenda for Future Research. The Winners 13, 10-114.

[6] E-learning Center - University "Goce Delcev", Stip, 2000, R.Macedonia, Kocaleva, M., Stojanovic, I., Zdravev, Z., 2015. Model of e-Learning Acceptance and Use for Teaching Staff in Higher Education Institutions. Int. J. Mod. Educ. Comput. Sci. 7, 23-31. doi:10.5815/ijmecs.2015.04.03

[7] Fatmasari, F., 2011. Implementasi e-learning system dengan menggunakan model unified theory of acceptance and use of technology (Studi Kasus: e-learning Universitas Bina Darma). J. Matriks 13, 49-64. 
[8] Faulina, S.T. et al, 2017. Perancangan dan evaluasi implementasi sistem informasi kepegawaian perguruan tinggi akmi baturaja. KNTIA 4.

[9] Gilbert, S.M., Jones, M.G., 2001. E-Learning Is E-Normous Training over the internet has become the fastest-growing workplace performance improvement tool-and utilities are using it in several ways. Electr. Perspect. 66-85.

[10] Handayani, T., Sudiana, S., 2017. Analisis penerapan model utaut (unified theory of acceptance and use of technology) terhadap perilaku pengguna sistem informasi (Studi Kasus: Sistem Informasi Akademik pada STTNAS Yogyakarta), in: Prosiding Seminar Nasional ReTII.

[11] Haris, D.A., Sugito, E., 2015. Analysis of factors affecting user acceptance of the implementation of ClassCraft ELearning: Case studies faculty of information technology of Tarumanagara university, in: Advanced Computer Science and Information Systems (ICACSIS), 2015 International Conference on. IEEE, pp. 73-78.

[12] Horton, W., Horton, K., 2003. E-learning tools and technologies: A consumer's guide for trainers, teachers, educators, and instructional designers. John Wiley \& Sons.

[13] Inayat, I., ul Amin, R., Inayat, Z., Salim, S.S., 2013. Effects of collaborative web based vocational education and training (VET) on learning outcomes. Comput. Educ. 68, 153-166.

[14] Khan, B.H., 2005. Managing e-learning: Design, delivery, implementation, and evaluation. IGI Global.

[15] Loogma, K., Kruusvall, J., Ümarik, M., 2012. E-learning as innovation: Exploring innovativeness of the VET teachers' community in Estonia. Comput. Educ. 58, 808-817.

[16] Maldonado, U.P.T., Khan, G.F., Moon, J., Rho, J.J., 2009. E-learning motivation, Students' Acceptance/Use of Educational Portal in Developing Countries: A Case Study of Peru. IEEE, pp. 1431-1441. doi:10.1109/ICCIT.2009.77

[17] Nasir, M., 2013. Evaluasi Penerimaan Teknologi Informasi Mahasiswa di Palembang Menggunakan Model UTAUT, in: Seminar Nasional Aplikasi Teknologi Informasi (SNATI).

[18] Ngampornchai, A., Adams, J., 2016. Students' acceptance and readiness for E-learning in Northeastern Thailand. Int. J.
Educ. Technol. High. Educ. 13. doi:10.1186/s41239-0160034-x

[19] Pamugar, H., Winarno, W.W., Najib, W., 2014. Model Evaluasi Kesuksesan dan Penerimaan Sistem Informasi ELearning pada Lembaga Diklat Pemerintah. Sci. J. Inform. $1,13-27$.

[20] Prasetyo, B.H., Anubhakti, D., 2011. Kajian Penerimaan Sistem E-Learning Dengan Menggunakan Pendekatan UTAUT Studi Kasus Fakultas Teknologi Informasi Universitas Budi Luhur. J. BIT Vol 8, 45-47.

[21] Riyana, R., Deni Kurniawan, C., 2011. Pembelajaran Berbasis Teknologi Informasi dan Komunikasi: Mengembangkan Profesionalitas Guru.

[22] Sedana, I.G.N., Wijaya, S.W., 2010. UTAUT model for understanding learning management system. Internetworking Indones. J. 2, 27-32.

[23] Surjono, H.D., 2013. The Implementation of ICT to Enhance Student Learning Activities, in: The International Conference on Computers in Education (ICCE). AsiaPacific Society for Computers in Education.

[24] Taiwo, A.A., DOWNE, A.G., 2013. The theory of user acceptance and use of technology (UTAUT): A metaanalytic review of empirical findings. J. Theor. Appl. Inf. Technol. 49.

[25] Venkatesh, V., Morris, M.G., Davis, G.B., Davis, F.D., 2003. User acceptance of information technology: Toward a unified view. MIS Q. 425-478.

[26] Venkatesh, V., Thong, J.Y., Xu, X., 2012. Consumer acceptance and use of information technology: extending the unified theory of acceptance and use of technology.

[27] Yulius, R., 2016. Efek moderasi kesukarelaan terhadap pembelajaran online pada universitas sahid surakarta. j. Ipteks Terap. 10. doi:10.22216/jit.2016.v10i4.534

[28] Zarini, M., 2009. Switched on: international approaches to skills development through ICTs, in: International Handbook of Education for the Changing World of Work. Springer, pp. 1935-1946 